NASA Technical Memorandum 107331

\title{
Prediction of Composite Laminate Fracture: Micromechanics and Progressive Fracture
}

P.K. Gotsis and C.C. Chamis

Lewis Research Center

Cleveland, Ohio

L. Minnetyan

Clarkson University

Potsdam, New York

December 1996

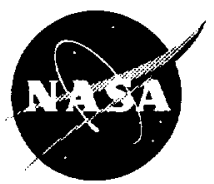

National Aeronautics and

Space Administration 
. 


\title{
PREDICTION OF COMPOSITE LAMINATE FRACTURE: MICROMECHANICS AND PROGRESSIVE FRACTURE
}

\author{
P.K. Gotsis and C.C. Chamis \\ National Aeronautics and Space Administration \\ Lewis Research Center \\ Cleveland, Ohio 44135 \\ L. Minnetyan \\ Clarkson University \\ Potsdam, New York 13699
}

\begin{abstract}
SUMMARY
This report describes an investigation to predict first-ply failure and final fracture in selected composite laminates subjected to inplane loads. The laminates were composed of glass fiber and graphite fibers in epoxy matrices. Failure envelopes based on first-ply failure and laminate fracture were generated for combined loading of these laminates. Predictions were evaluated by micromechanics-based theory and progressive fracture. The results show that, for most cases, combined tensile loading significantly enhanced the laminate fracture stress in comparison to the uniaxial loading.
\end{abstract}

\section{INTRODUCTION}

One of the persistent difficulties in composite design and analysis has been the inability to predict laminate fracture under uniaxial and/or combined loading by using either unidirectional composite (ply) data or micromechanics with pristine constituent material properties. The difficulty has been compounded many times over by the existence of many and diverse failure criteria. Thus it became apparent that a formalized comparison of the various failure theories to the measured data would be instructive and very useful.

To that end, A.J. Hinton (Head of the Advanced Composite Structures Team, DRA, Fort Halstead, UK) and P.D. Soden (Senior Lecturer in Mechanical Engineering, UMIST, UK) organized an exercise to confirm state-ofthe-art methods for predicting failure in composites. World-renown researchers in the failure of composites were invited to participate. The organizers provided them with (1) a list of laminates, (2) unidirectional composite data, (3) pristine constituent material properties, (4) unidirectional composite stress-strain curves, and (5) recommended standardized formats to present their results. Results shown in the various figures in this report comply with the recommended formats. The objective of this report is to describe the results we obtained during our participation in that exercise.

Our contribution to this exercise consisted of two major parts: (1) using the micromechanics-based uniaxial composite strengths described herein to generate first-ply failure envelopes for combined loading, and (2) using progressive fracture to generate laminate fracture envelopes and stress-strain diagrams for uniaxial and combined loading. The effects of residual stresses on laminate first-ply failure were evaluated, as were the differences between pristine and in situ constituent properties. The pristine constituent material properties were calibrated to the unidirectional composite properties so that the micromechanics used would reproduce the unidirectional composite properties provided. Details are described in this report, along with the specific theories and computer codes used.

The laminate failure envelopes were generated by two computer codes: (1) the Integrated Composite Analyzer (ICAN) and (2) the Composite Durability Structural Analyzer (CODSTRAN). For completeness, these computer codes are briefly described in the following sections. 


\section{ICAN COMPUTER CODE}

The authors have conducted extensive research at NASA Lewis Research Center, developing composite mechanics theories and analysis methods ranging from micromechanics to finite elements. These theories and analysis methods account for environmental effects and are applicable to intraply hybrid composites, interply hybrid composites, and combinations therefrom. Most of these theories are represented by simplified equations and have been corroborated by experimental results and finite-element analysis. The composite mechanics theories, with their simplified equations, constitute a structured multiscale formalism that is (1) "upward integrated" (synthesized) from material behavior space to structural analysis and (2) "top-down traced" (decomposed) from structural response to material behavior space (see fig. 1).

This theory has been incorporated into a computer code called ICAN (Integrated Composite Analyzer). The following paragraphs give a brief history of the developments in composite mechanics and the related computer codes that led to the evolution of ICAN.

The need for multilevel (multiscale) analysis in designing structural components made of multilayered fiber composites was recognized about 30 years ago (ref. 1). Shortly thereafter, a multilevel analysis computer code (Multilayered Fiber Composite Analysis (MFCA)) was developed; it was found to be efficient in predicting the structural response of multilayered fiber composites, given the constituent materials properties, the fabrication process, and the composite geometry (see ref. 2).

Since intraply hybrid composites were the logical sequel to conventional and interply hybrid composites, theoretical and experimental investigations were subsequently conducted on the mechanical behavior of intraply hybrids (refs. 3 to 5). The theoretical methods and equations described in references 3 to 5 , together with those for hygrothermal effects (ref. 6), have been integrated into a computer code that predicts hygral, thermal, and mechanical properties of intraply hybrid composites, thereby enabling their "design." The computer code is called "INtraply HYbrid Composite Design," or INHYD (ref. 7).

The ICAN computer code is a synergistic combination of MFCA and INHYD, along with several significant enhancements. It utilizes the micromechanics embodied in INHYD and the laminate theory of MFCA to build a comprehensive analysis and design capability for structural composites. ICAN also offers the following unique features:

(1) Ply stress-strain influence coefficients

(2) Microstresses and microstress influence coefficients

(3) Stress concentration factors at a circular hole

(4) Predictions of probable delamination locations around a circular hole

(5) Poisson's ratio mismatch details near a straight free edge

(6) Free-edge stresses

(7) Material cards to be implemented as input for finite-element analysis by several commercial computer codes

(8) Laminate failure stresses based on first-ply failure and fiber-breakage criteria, with and without hygrothermal degradation

(9) Transverse shear stresses and normal stresses

(10) Explicit specification of interply layers

In addition, ICAN has its own (dedicated) data bank of material properties for commonly used fibers and matrices, which can be easily modified by the user to add new constituent materials.

ICAN is primarily designed to analyze the hygrothermomechanical response and the properties of fiberreinforced/resin-matrix layered composites, given the local membrane loads and bending moments. Three types of layers are recognized by the program: (1) a layer in the standard composite system, which consists entirely of a primary composite made of one type of fiber and matrix; (2) a layer in the intraply hybrid composite system, which consists of a primary composite and a secondary composite arranged in a prescribed manner within a layer (for purposes of identification, the primary composite in the hybrid is the one that constitutes the largest volume ratio); and (3) the interply layer, which consists of a matrix only.

Complete details of the equations in the code are given in reference 8. The composite hygrothermomechanical properties can be predicted by using the micromechanics theories mentioned previously. Laminate properties are obtained with macromechanics and laminate theory, and local stresses and strains are determined from classical laminate theory. The free-edge stress calculations are based on the approach outlined in reference 9, with enhancements to accommodate the interply layer and the local characteristics of the adjacent ply. The stress concentration 
factors around a circular hole are obtained by using the equations given in reference 10. Laminate failure stress analysis utilizes two criteria: (1) first-ply failure based on maximum strength and (2) first-ply failure based on fiber breakage. Complete laminate failure analysis uses two different ply combined-stress failure criteria and one interply delamination criterion for each specified load condition.

\section{CODSTRAN COMPUTER CODE}

CODSTRAN is an integrated computer code based on a new approach to progressive fracture of composite laminates and structures. It evolved from the following observations and/or concepts: (1) Any laminate or structural component can sustain a certain amount of damage prior to structural fracture (collapse). (2) During damage propagation, the laminate or component exhibits progressive degradation of structural integrity as measured by global structural behavior variables, such as loss of frequency, loss of buckling resistance, or excessive displacements. (3) The critical damage can be defined as the amount of damage beyond which degradation of the laminate structural integrity is very rapid, having been induced by either a small amount of additional damage or a slight increase in loading. (4) Laminate damage is characterized by the following sequence: damage initiation, growth, accumulation, stable or slow propagation (up to the critical amount), and unstable or very rapid propagation (beyond the critical amount) to collapse.

These concepts are fundamental to developing formal procedures to identify the different stages of damage, quantify the amount of damage at each stage, and relate the degradation of global structural behavior to the amount of damage at each stage.

CODSTRAN is a combination of composite mechanics (ICAN, ref. 8) and the finite-element method MHOST (ref. 11). It permits a simulation of local behavior as well as global structural behavior through an integrated computer code, which is shown schematically in figure 1 . The lower part of this figure describes the constituent properties as functions of environmental and mechanical loading conditions. The criteria can be implemented by knowing the developed ply stresses, and ply strength can predict the damage initiation, growth, accumulation, and propagation. As a result, the constituent properties are updated at every load increment. For example, if the ply longitudinal stress exceeds the allowable strength, then the fiber/matrix longitudinal moduli are replaced by negligible values so that, in essence, the ply does not carry any load and the stresses are redistributed to the surrounding plies. However, if a particular ply's transverse strength exceeds its allowable strength, then only the matrix is assumed to have failed and the matrix modulus is replaced with a negligible value. Once the current constituent properties are determined (as in the left part of fig. 1), repeated applications of micromechanics, macromechanics, and laminate theory are used to assemble the global structural stiffness matrix, which is fed into the finite-element analysis. Thus, the left part of the figure depicts the integration (synthesis) of local damage conditions to global structural behavior (response).

The nodal stress resultants are the outcome of the finite-element analysis. They are used to decompose the changes in the global response (e.g., laminate stresses and strains that result from incremental load or stiffness changes) on the local (micro) material stress/resistance. The load is incrementally increased only if there is no further damage due to changes in ply level stresses. Otherwise, only the material properties at the constituent level are updated at every iteration until a balance is reached between the applied loading and the local response. Overall structural equilibrium is maintained by iterations around the "cartwheel" until a specified convergence is reached. This procedure is illustrated in figure 2 . The final result in terms of load as a function of global displacement is shown in figure 3 . The schematics in figures 1 to 3 , collectively summarize the fundamentals and implementation of this computational simulation of structural fracture in composites and composite laminates.

\section{MODIFICATION OF CONSTITUENT PROPERTIES}

In order to take full advantage of the simulation capabilities of ICAN and CODSTRAN, and since both of these computer codes are micromechanics (constituent materials) based, we modified the constituent materials provided by the organizers (tables I and II) so as to match the predicted composite unidirectional (ply) properties as shown in table III. A good reason for basing the ICAN/CODSTRAN simulations on micromechanics is that the in situ properties of the constituents generally differ from those of their pristine state (ref. 12). The modified constituent properties we obtained and used are shown in tables I and II. A comparison of values for the matrix properties (see table I) 
shows a substantial difference in matrix strength properties. Overall, the tensile strengths are about 50 percent lower, whereas the compressive strengths for the DFVLR matrix are about 30 percent higher. The shear strengths are also higher. The interesting point is that if the in situ matrix retains its pristine tensile strength, then the substantial tensile strength reduction could be caused by cracking due to thermal mismatch during the processing. The fiber properties (see table II) are about the same for both the as-provided and the calibrated cases. The unidirectional composite properties (table III) are almost identical.

\section{ICAN SIMULATION RESULTS}

Herein we summarize the simulation results obtained for biaxial stress failure envelopes by using the ICANmodified constituent properties (table I) and first-ply failure.

\section{Unidirectional Laminates}

Biaxial failure stress envelopes were determined for a number of laminates. Figure 4 shows the envelope of an E-Glass/LY556 unidirectional composite subjected to transverse and shear loading $\left(\sigma_{y}\right.$ versus $\tau_{x y}$ ). Since this failure envelope is symmetric about the $\sigma_{y}$-axis, only the upper half is shown. The biaxial failure stress envelope for the T300/BSL914C unidirectional laminate subjected to longitudinal and shear loading $\left(\sigma_{x}\right.$ versus $\left.\tau_{x y}\right)$ is shown in figure 5. It too is symmetric about the $\sigma_{x}$-axis, so only the upper half is plotted.

The biaxial failure stress envelope for the E_Glass/MY750 unidirectional laminate subjected to biaxial longitudinal and transverse loading $\left(\sigma_{x}\right.$ versus $\left.\sigma_{y}\right)$ is shown in figure 6 . This failure envelope shows discontinuities from the tension-compression to tension-tension quadrants and from the compression-tension to compression-compression quadrants. The discontinuities are accentuated because of the large difference between the longitudinal and transverse tensile and compressive strengths.

\section{Angle-Ply Laminates}

The biaxial failure stress envelope for the E-Glass/LY556 $\left[90^{\circ} \% 30^{\circ}\right]_{\mathrm{s}}$ laminate subjected to a biaxial loading $\left(\sigma_{y}\right.$ versus $\sigma_{x}$ ) stress state is shown in figure 7 . Note that this failure envelope was generated by first-ply failure. This laminate is strong in compression, but relatively weak in tension.

The biaxial failure stress envelope for E-Glass/LY556 $\left[90^{\circ} / \pm 30^{\circ}\right]_{s}$ subjected to biaxial loading $\left(\tau_{x y}\right.$ versus $\left.\sigma_{x}\right)$ is shown in figure 8 . This envelope, which is based on first-ply failure, is symmetric about the $\sigma_{x}$-axis, so only the upper half is plotted. The laminate is weak in both tension and shear, but strong in $\sigma_{x}$ compression.

The biaxial failure stress envelope for the E-Glass/MY750 $\left[ \pm 55^{\circ}\right]_{s}$ laminate subjected to $\sigma_{x}$ and $\sigma_{y}$ combined loading is shown in figure 9. This laminate is strong in $\sigma_{y}$ tension in the $\sigma_{y}, \sigma_{x}$ compression-compression quadrant.

The biaxial failure stress envelope for the AS4/epoxy 3501-6 $\left[90^{\circ} / 45^{\circ} / 0^{\circ}\right]_{\mathrm{s}}$ laminate subjected to biaxial loading $\left(\sigma_{x}\right.$ versus $\left.\sigma_{y}\right)$ is shown in figure 10 . Note that this laminate is ultrastrong in the compression-compression quadrant, with the different types of combined loadings having a substantial synergistic effect in this quadrant. In the tensiontension quadrant the laminate is moderately strong, whereas in the second and fourth quadrants, it is weak.

\section{Effects of Thermal Stresses}

All the laminate failure envelopes were generated without accounting for residual stresses from lamination. These stresses result from the curing temperature differential and the thermal expansion coefficient (TEC) mismatch. It is instructive, therefore, to evaluate the effects of residual stresses on at least one failure envelope. Figure 11 shows the failure envelope for the AS4/epoxy 3501-6 $\left[90^{\circ} / \pm 45^{\circ} / 0^{\circ}\right]_{\mathrm{S}}$ replotted in full scale both with and without residual stresses. The residual stresses have a dramatic effect on the laminate biaxial failure stress envelope in the three quadrants that have tensile stresses. This is an expected result because the plies in quasi-isotropic laminates have relatively high transverse ply stresses due to curing temperature differential and TEC mismatch. It should also be noted that resistance increased in the compression quadrant. 


\section{CODSTRAN SIMULATION RESULTS}

CODSTRAN simulation results are presented here for one unidirectional composite (for comparison purposes only) and for all the angle-ply laminates.

\section{Unidirectional Laminate}

The failure envelope generated by plotting CODSTRAN results is shown in figure 12 . The plate was $10 \mathrm{~mm}$ wide by $10 \mathrm{~mm}$ long by $1 \mathrm{~mm}$ thick. The biaxial failure envelope was generated for $\tau_{x y}$ versus $\sigma_{y}$. Although there are not enough points to obtain a smooth function, the points shown are exactly the same as in figure 4 . This was an expected result since both CODSTRAN and ICAN use the same combined-stress failure criterion, which is stress based (ref. 13). From this we can conclude that linear composite mechanics is sufficient to develop combined-stress failure envelopes of unidirectional laminates subjected to combined loading.

\section{Angle-Ply Laminates}

Two combined-stress failure envelopes predicted by using the progressive fracture feature in CODSTRAN are shown in figure 13 for the E-Glass $/ \mathrm{LY} 556\left[90^{\circ} / \pm 30^{\circ}\right]_{\mathrm{s}}$ laminate subjected to combined $\sigma_{x}$ versus $\sigma_{y}$ loading (as in fig. 7). The inner envelope is the initial damage failure envelope, and the outer one is the laminate fracture envelope. In figure 13 the initial damage envelope includes residual stresses, whereas in figure 7 it does not. Clearly, the residual stresses significantly affect the first-ply failure in quadrants with tensile stresses but do not affect the compression-compression quadrant, and the tensile stresses that cause laminate fracture are about 10 times those that cause first-ply failure. From this, two important conclusions may be drawn: (1) multi-ply laminates designed for first-ply failure under $\sigma_{x}$ versus $\sigma_{y}$ (tension-tension loading) will be significantly overdesigned; and (2) multi-ply laminates subjected to monotonic single loads to fracture must be designed by using progressive fracture analysis for cost-effective composite utilization.

The CODSTRAN-simulated combined-stress failure envelopes for the E-Glass $/ \mathrm{LY} 556\left[90^{\circ} \pm 30^{\circ}\right]_{\mathrm{s}}$ laminate subjected to combined $\left(\tau_{x y}\right.$ versus $\sigma_{x}$ ) loading is shown in figure 14. The CODSTRAN simulations include residual stresses, which are significant contributors to first-ply failure. Comparing the inner failure envelope in figure 14 with that in figure 8 shows that residual stresses decrease the laminate's first-ply tensile and shear failures by a factor of about 3. In addition, figure 14 shows that (1) progressive fracture (suitable for monotonic load) dramatically expands the tensile quadrant of the laminate failure envelope by a factor of about 15 ; and (2) the progressive fracture combined-stress failure envelope is not a smooth function because (a) the stress is redistributed following a local fracture, (b) the various failure modes are discrete and, therefore, not continuous, and (c) the jumps occur as the fracture progresses from one failure mode to the next. In summary, the important facts are (1) the laminate reserve strength from first-ply failure to laminate fracture is substantial when the laminate is loaded in combined shear and tension and (2) the laminate combined-stress fracture envelope is not a smooth function.

Two laminate failure envelopes for combined $\sigma_{x}$ and $\sigma_{y}$ loading of the E-Glass/MY750 $\left[ \pm 55^{\circ}\right]_{s}$ laminate are shown in figure 15 . The inner envelope represents initial damage, and the outer one, laminate fracture. Interestingly, the two envelopes are practically identical when $\sigma_{x}$ and $\sigma_{y}$ are both tensile. The observations and conclusions made in connection with figures 13 and 14 apply to figure 15 as well.

\section{Stress Versus Strain}

In this section we describe stress versus strain, as determined by progressive fracture via CODSTRAN. The stress-strain curves for all cases except one were obtained without including the effects of residual stresses. For that one case, the effects of residual stress were included.

The stress-strain curve for the E-Glass/MY750 $\left[ \pm 55^{\circ}\right]_{\mathrm{S}}$ laminate is shown in figure 16. This laminate exhibits bilinear behavior: The first portion is linear up to a strain of about 0.5 percent; then the strain increases very rapidly up to 12 percent, or 24 times more, with a relatively small increase in stress (only 20 percent). The failure strain of 
about 12-percent may be misleading because it occurs with relatively small load increments. In other words, laminate fracture was imminent past the 0.5 percent strain. One can infer from this that laminate configurations can exist with large strains before fracturing. Keep in mind, however, that this large strain is useful only for monotonic loading to fracture. The important conclusion is that progressive fracture is a suitable method for generating laminate stress-strain curves to fracture.

Two stress-strain curves are shown in figure 17, where $\sigma_{y}$ is plotted versus $\varepsilon_{y}$ and $\varepsilon_{x}$ for the E-Glass/MY750 $\left[ \pm 55^{\circ}\right]_{s}$ laminate: The $\varepsilon_{y}$ strain is along the $y$-load direction, and the $\varepsilon_{x}$ strain is along the $x$-load direction. Both curves are practically linear until fracture, with the $\varepsilon_{x}$ strain exhibiting a minor deviation from linearity near the high strain region. It is interesting to note that the biaxial stress and strain reduced the fracture strain by a factor of 4 compared to the uniaxial loading shown in figure 16 while increasing the corresponding fracture stress by a factor of 6 .

Obviously, the stress-strain behavior of angle-ply laminates is dramatically different under combined loading in comparison to uniaxial loading.

The stress-strain curve for uniaxial loading of the AS4/3501-6 $\left[0^{\circ} / 445^{\circ} / 90^{\circ}\right]_{S}$ laminate is plotted in figure 18 . This figure shows trilinear behavior. However, the last portion, beyond 1-percent strain occurs with a very small increase in stress and happens very fast. The important feature is the nonlinear stress-strain behavior to fracture that the AS4/3501-6 $\left[0^{\circ} / \pm 45^{\circ} / 90^{\circ}\right]_{s}$ laminate exhibits. The first linear portion ends at about 0.25 -percent strain, which corresponds to trans-ply fracture in both the $90^{\circ}$ and the $\pm 45^{\circ}$ plies. The second portion ends at about 1.0-percent strain, which corresponds to about 70 percent of the fracture strain of the fibers (see table II).

The stress-strain curve for the AS4/3501-6 $\left[0^{\circ} / 45^{\circ} / 90^{\circ}\right]_{\mathrm{s}}$ laminate subjected to combined-stress loading $\left(\sigma_{y} / \sigma_{x}=2 / 1\right)$ is shown in figure 19. This stress-strain curve is linear to fracture at about 1.5 percent strain, which corresponds to the fracture strain of the AS4 fibers (table II). The fracture stress is about twice that of the uniaxial case (fig. 19). This shows that some biaxial stress states substantially enhance the fracture stress of quasi-isotropic laminates. Unfortunately, the magnitude of the enhancement is load dependent and can be taken advantage of only for monotonic loadings to fracture.

The stress-strain behavior of the E-Glass/MY750 $\left[ \pm 45^{\circ}\right]_{s}$ laminate subjected to combined $\sigma_{y} / \sigma_{x}=1 / 1$ loading is shown in figure 20. The useful fracture strain for this angle-ply laminate is about 2.5 percent, which is at the end of the first linear portion. Beyond this point the strain increases rapidly to about 6 percent with a relatively negligible increase in stress. The useful fracture strain of 2.5 percent corresponds to the strain just before the shear stress-strain curve becomes linear. Again we see that biaxial tensile loading enhances the fracture stress of $\left[ \pm 45^{\circ}\right]_{s}$ angle-ply laminates, as it did for the $\left[ \pm 55^{\circ}\right]_{s}$ angle-ply laminate (fig. 17).

The stress-strain curves for the E-Glass/MY750 $\left[ \pm 45^{\circ}\right]_{s}$ angle-ply laminate subjected to biaxial $\sigma_{y} / \sigma_{x}=1 /-1$ loading is shown in figure 21 . Both stress-strain curves are linear to fracture at about 0.4 -percent strain. This strain is considerably smaller than that in the tension loading case (fig. 20). The important conclusion is that fracture stressstrain of angle-ply laminates under biaxial loads with mixed signs (tension-compression) is substantially loweronly about 10 percent of that of the tension-tension cases.

The stress-strain curve for the E-Glass/MY750 $\left[0^{\circ} / 90^{\circ}\right]_{\mathrm{s}}$ cross-ply laminate subjected to uniaxial loading $\sigma_{y} / \sigma_{x}=0 / 1$ is shown in figure 22. The stress-strain curve is linear to fracture at about 2-percent fracture strain, which is about 80 percent of the tensile fracture strain of the fiber (table II). And the fracture stress is about one-half of the fracture stress of the unidirectional laminate (table III). From this we may conclude that (1) cross-ply laminates loaded in uniaxial tension fracture at about one-half the developed tensile fracture stress of the uniaxial laminate and (2) cross-plying does not affect the linear stress-strain behavior of the unidirectional laminate.

\section{SUMMARY OF RESULTS}

An investigation was conducted to evaluate the first-ply failure and laminate fracture of selected laminates made from glass/epoxy and graphite/epoxy fiber polymer matrix composites that were subjected to uniaxial and combined loadings. The evaluation employed laminate theory for first-ply failure and progressive fracture for laminate fracture. Both are based on micromechanics and require constituent material (fiber and matrix) properties as inputs, as well as fiber volume ratio, void volume ratio (if any), and cure temperature.

The following are the most important results from this investigation: 
1. For unidirectional composites (ply), first-ply failure and laminate fracture were identical. Laminate theory was sufficient to evaluate behavior for uniaxial and combined loadings.

2. For multi-ply laminates (angle-ply or multidirectional), laminate theory is sufficient to evaluate first-ply failure. However progressive fracture is required to determine laminate fracture.

3. In angle-ply and multidirectional laminates, residual stresses dramatically reduce first-ply failure in predominant tensile stress states; however, their effects on laminate fracture stress are more benign.

4. In comparison to uniaxial loading, combined tension and compression loadings had a negligible enhancement effect on laminate fracture stress.

5. Angle-ply laminates loaded in biaxial tension exhibited substantial strain to fracture beyond the initial linear portion. This strain occurs with very small load increases.

6. The pristine strength of the fibers was not exhibited in any of the laminates. Fiber fractures occurred at about 70 to 80 percent of their respective pristine fracture strains.

\section{REFERENCES}

1. Chamis, C.C.: Design Oriented Analysis and Synthesis of Multilayered-Filamentary Structural Panels. Ph.D. Thesis, Case Western Reserve University, 1967.

2. Chamis, C.C.: Computer Code for the Analysis of Multilayered Fiber Composites-User's Manual. NASA TN D-7013, 1971.

3. Chamis, C.C.; and Sinclair, J.H.: Prediction of Properties of Intraply Hybrid Composites. NASA TM-79087, 1979.

4. Chamis, C.C.; and Sinclair, J.H.: Micromechanics of Intraply Hybrid Composites: Elastic and Thermal Properties. NASA TM-79253, 1979.

5. Chamis, C.C.; Lark, R.F.; and Sinclair, J.H.: Mechanical Property Characterization of Intraply Hybrid Composites. NASA TM-79306, 1979.

6. Chamis, C.C.; Lark, R.F.; and Sinclair, J.H.: An Integrated Theory for Predicting the Hydrothermomechanical Response of Advanced Composite Structural Components. NASA TM-73812, 1977.

7. Chamis, C.C.; and Sinclair, J.H.: INHYD: Computer Code for Intraply Hybrid Composite Design. NASA TP-2239, 1983.

8. Murthy, P.L.N.; and Chamis, C.C.: Integrated Composite Analyzer (ICAN) Users and Programmers Manual. NASA TP-2515, 1985.

9. Pagano, N.J.; and Pipes, R.B.: Some Observations on the Interlaminar Strength of Composite Laminates. Int. J. Mech. Sci., vol. 15, no. 8, 1973, pp. 679-688.

10. Lekhnitskii, S.G.: Theory of Elasticity of an Anisotropic Elastic Body. Holden-Day, San Francisco, CA, 1963.

11. Nakazawa, S.: The MHOST Finite Element Program: Inelastic Analysis Methods for Hot Section Components. Volume 2: Users' Manual. NASA CR-182235, 1987.

12. Chamis, C.C.; and Sinclair, J.H: Durability/Life of Fiber Composites in Hygrothermomechanical Environments. ASTM STP-787, 1982, pp. 498-512.

13. Chamis, C.C.: Failure Criteria for Filamentary Composites. ASTM, STP-460, 1969, pp. 336-351. 
TABLE I.-MECHANICAL PROPERTIES OF VARIOUS MATRICES

\begin{tabular}{|c|c|c|c|c|c|c|c|c|}
\hline \multirow[t]{3}{*}{ Property } & \multicolumn{8}{|c|}{ Matrix } \\
\hline & \multicolumn{2}{|c|}{$\begin{array}{l}\text { Hercules 3501-6 } \\
\text { epoxy }\end{array}$} & \multicolumn{2}{|c|}{$\begin{array}{c}\text { DFVLR BSL914C } \\
\text { epoxy }\end{array}$} & \multicolumn{2}{|c|}{$\begin{array}{c}\text { Ciba Geigy } \\
\text { LY556/HT907/DY063 } \\
\text { epoxy }\end{array}$} & \multicolumn{2}{|c|}{$\begin{array}{c}\text { Ciba Geigy } \\
\text { My750/HY917/DY063 } \\
\text { epoxy } \\
\end{array}$} \\
\hline & Pristine & ICAN & Pristine & ICAN & Pristine & ICAN & Pristine & ICAN \\
\hline Modulus, GPa & 4.2 & 5.8 & 4.0 & 5.724 & 3.35 & 4.772 & 3.35 & 4.2827 \\
\hline Shear modulus, GPa & 1.56 & (a) & 1.481 & (a) & 1.24 & (a) & 1.24 & (a) \\
\hline Poisson's ratio & 0.34 & 0.38 & 0.35 & 0.398 & 0.35 & 0.4 & 0.35 & 0.4 \\
\hline Strength, MPa & & & & & & & & \\
\hline Tensile & 69 & 53.75 & 75 & 30.26 & 80 & 41.79 & 80 & 47.92 \\
\hline Compressive & 250 & 223.9 & 150 & 224.13 & 120 & 137.2 & 120 & 173.7 \\
\hline Shear & 50 & 94.068 & 70 & 93.79 & $\ldots$ & 86.89 & ----- & 87.5 \\
\hline Tensile failure strain, percent & 1.7 & ----- & & ---- & & ----- & 5 & $\ldots-\cdots$ \\
\hline Thermal coefficient, ${ }^{\circ} \mathrm{C}^{-1}$ & $45 \times 10^{-6}$ & $43.2 \times 10^{-6}$ & $55^{-} \times 10^{-6}$ & $45 \times 10^{-6}$ & $58 \times 10^{-6}$ & $64.8 \times 10^{-6}$ & $58 \times 10^{6}$ & $52.38 \times 10^{-6}$ \\
\hline
\end{tabular}

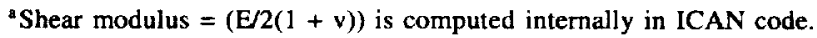

TABLE II-MECHANICAL PROPERTIES OF VARIOUS FIBERS

\begin{tabular}{|c|c|c|c|c|c|c|c|c|}
\hline \multirow[t]{3}{*}{ Property } & \multicolumn{8}{|c|}{ Fiber } \\
\hline & \multicolumn{2}{|c|}{ AS4 } & \multicolumn{2}{|c|}{$\mathrm{T} 300$} & \multicolumn{2}{|c|}{$\begin{array}{c}\text { Geretex E-glass } \\
21 \mathrm{XK} 43 \\
\end{array}$} & \multicolumn{2}{|c|}{ Silenka E-glass 1200 tex } \\
\hline & Pristine & ICAN & Pristine & ICAN & Pristine & ICAN & Pristine & ICAN \\
\hline Modulus, GPa & & & & & & & & \\
\hline Longitudinal & 225 & 208.34 & 230 & 220.68 & 80 & 85.862 & 74 & 73.1 \\
\hline Transverse & 15 & 14.96 & 15 & 14.965 & 80 & 83.860 & 74 & 81.72 \\
\hline \multicolumn{9}{|l|}{ Shear modulus, GPa } \\
\hline Inplane & 15 & 14.96 & 15 & 14.965 & 33.33 & 33.31 & 30.8 & 30.8 \\
\hline Transverse & 7 & 6.9 & 7 & 6.965 & 33.33 & 32.62 & 30.8 & 30.8 \\
\hline Major Poisson's ratio & 0.2 & 0.2 & 0.2 & 0.2 & 0.2 & 0.2 & 0.2 & 0.2 \\
\hline \multicolumn{9}{|c|}{ Longitudinal strength, MPa } \\
\hline Tensile & 3350 & 3282.7 & 2500 & 2496 & 2150 & 1889 & 2150 & 2124 \\
\hline Compressive & 2500 & 6455 & 2000 & 2034.48 & 1450 & 1786 & 1450 & 1310 \\
\hline \multicolumn{9}{|c|}{ Longitudinal failure strain, percent } \\
\hline Tensile & 1.488 & $--\cdots--$ & 1.086 & ------ & 2.687 & ----- & 2.905 & ------- \\
\hline Compressive & 1.111 & $-\cdots----$ & 0.868 & ------ & 1.813 & ------ & 1.959 & $\ldots \ldots$ \\
\hline \multicolumn{9}{|c|}{ Thermal coefficient, ${ }^{\circ} \mathrm{C}^{-1}$} \\
\hline Longitudinal & $-0.5 \times 10^{-6}$ & $-1.818 \times 10^{-6}$ & $-0.7 \times 10^{-6}$ & $-1.773 \times 10^{-6}$ & $4.9 \times 10^{-6}$ & $6.633 \times 10^{-6}$ & $4.9 \times 10^{-6}$ & $6.822 \times 10^{-6}$ \\
\hline Transverse & $15 \times 10^{-6}$ & $16.182 \times 10^{-6}$ & $12 \times 10^{-6}$ & $12 \times 10^{-6}$ & $4.9 \times 10^{-6}$ & $4.86 \times 10^{-6}$ & $4.9 \times 10^{-6}$ & $11.16 \times 10^{-6}$ \\
\hline
\end{tabular}

TABLE III.-MECHANICAL PROPERTIES OF VARIOUS PLIES

\begin{tabular}{|c|c|c|c|c|c|c|c|c|}
\hline \multirow[t]{3}{*}{ Property } & \multicolumn{8}{|c|}{$\begin{array}{l}\text { Fiber/matrix } \\
\end{array}$} \\
\hline & \multicolumn{2}{|c|}{$\begin{array}{l}\text { AS4/Hercules } \\
\text { 3501-6 epoxy }\end{array}$} & \multicolumn{2}{|c|}{$\begin{array}{l}\text { T300/DFVLR } \\
\text { BSL914C epoxy }\end{array}$} & \multicolumn{2}{|c|}{$\begin{array}{c}\text { Geretex E-glass } \\
\text { 21XK43/Ciba Geigy } \\
\text { LY556/HT907/DY063 } \\
\text { epoxy }\end{array}$} & \multicolumn{2}{|c|}{$\begin{array}{c}\text { Silenka E-glass } 1200 \text { tex } \\
\text { Ciba Geigy } \\
\text { MY750/HY917DY } 063 \\
\text { epoxy }\end{array}$} \\
\hline & Pristine & ICAN & Pristine & ICAN & Pristine & ICAN & Pristine & ICAN \\
\hline Fiber content, vol\% & 60 & 60 & 60 & 60 & 62 & 62 & 60 & 60 \\
\hline Modulus, GPa & & & & & & & & \\
\hline Longitudinal & 126 & 127.309 & 138 & 140 & 53.48 & 53.37 & 45.6 & 45.634 \\
\hline Transverse & 11 & 11 & 11 & 11 & 17.7 & 17.57 & 16.2 & 16.206 \\
\hline Inplane shear modulus, GPa & 6.6 & 6.289 & 5.5 & 6.248 & 5.83 & 6.427 & 5.83 & 5.937 \\
\hline Poisson' ratio & & & & & & & & \\
\hline Major & 0.28 & 0.272 & 0.28 & 0.27 & 0.278 & 0.28 & 0.278 & 0.279 \\
\hline Through thickness & 0.4 & 0.414 & 0.4 & 0.44 & 0.4 & 0.403 & 0.4 & 0.415 \\
\hline Longitudinal strength, MPa & & & & & & & & \\
\hline Tensile & 1950 & 1969 & 1500 & 1500 & 1140 & 1131 & 1280 & 1295 \\
\hline Compressive & 1480 & 1480 & 900 & 900 & 570 & 570 & 800 & 800 \\
\hline Transverse strength, MPa & & & & & & & & \\
\hline Tensile & 48 & 48 & 27 & 27 & 35 & 35 & 40 & 40 \\
\hline Compressive & 200 & 200 & 200 & 200 & 114 & 114.48 & 145 & 144.964 \\
\hline Inplane shear strength, $\mathrm{MPa}$ & 79 & 79.93 & 80 & 80 & 72 & 72.413 & 73 & 73 \\
\hline Thermal coefficient, ${ }^{\circ} \mathrm{C}^{-1}$ & & & & & & & & \\
\hline Longitudinal & $-0.1 \times 10^{-6}$ & $-0.1 \times 10^{-6}$ & $-0.1 \times 10^{-6}$ & $-0.940 \times 10^{-6}$ & $8.6 \times 10^{-6}$ & $8.6 \times 10^{-6}$ & $8.6 \times 10^{-6}$ & $8.64 \times 10^{-6}$ \\
\hline Transverse & $26 \times 10^{-6}$ & $26 \times 10^{-6}$ & $26 \times 10^{-6}$ & $26.24 \times 10^{-6}$ & $26.4 \times 10^{-6}$ & $26.26 \times 10^{-6}$ & $26.4 \times 10^{-6}$ & $26.28 \times 10^{-6}$ \\
\hline
\end{tabular}




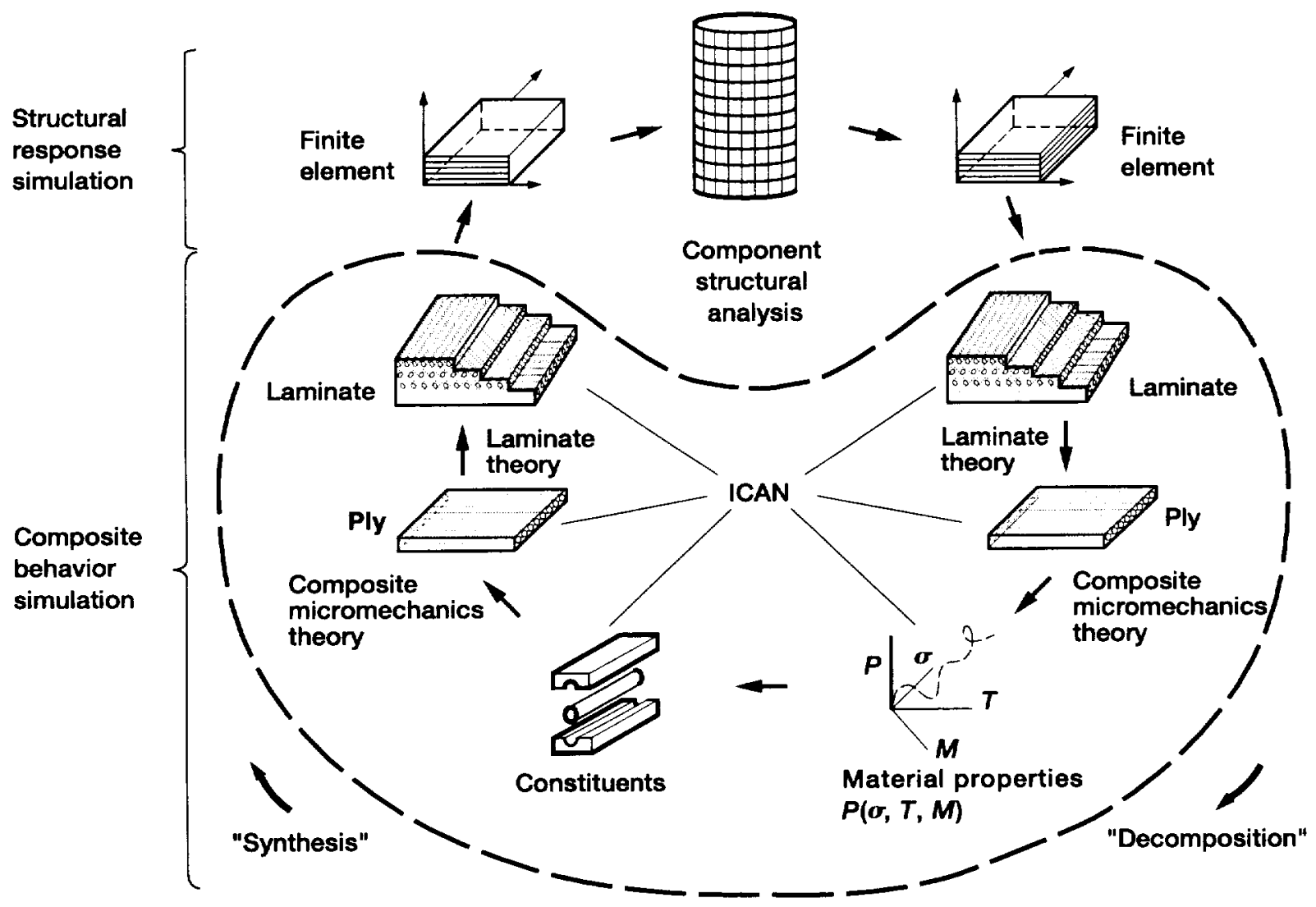

Figure 1.-Simulation cycle of progressive fracture in composite laminates and structures via CODSTRAN.

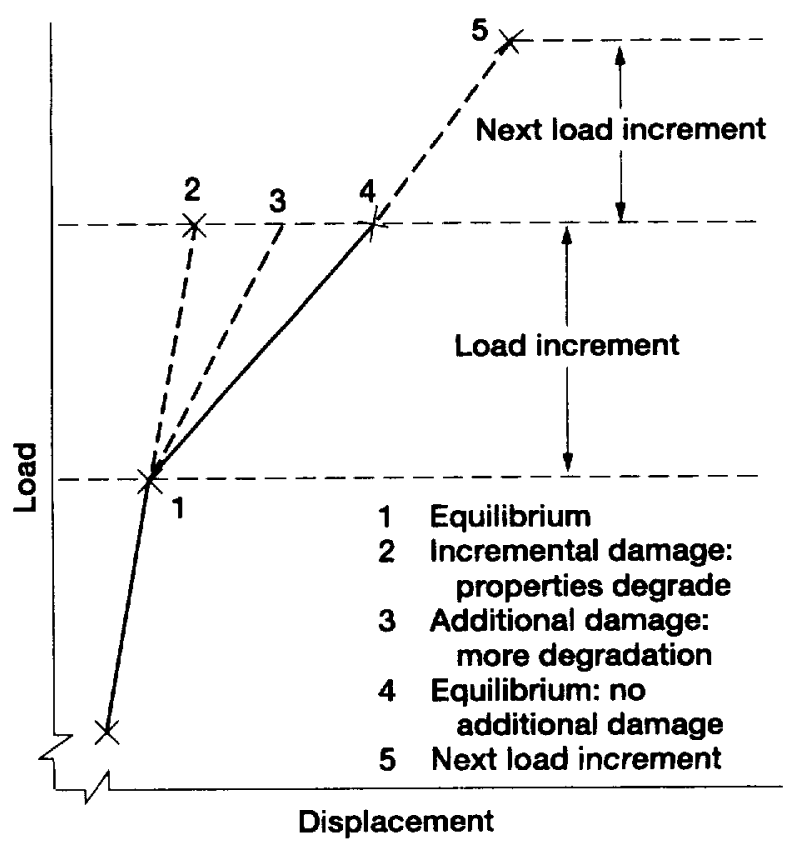

Figure 2.-CODSTRAN load incrementation. 


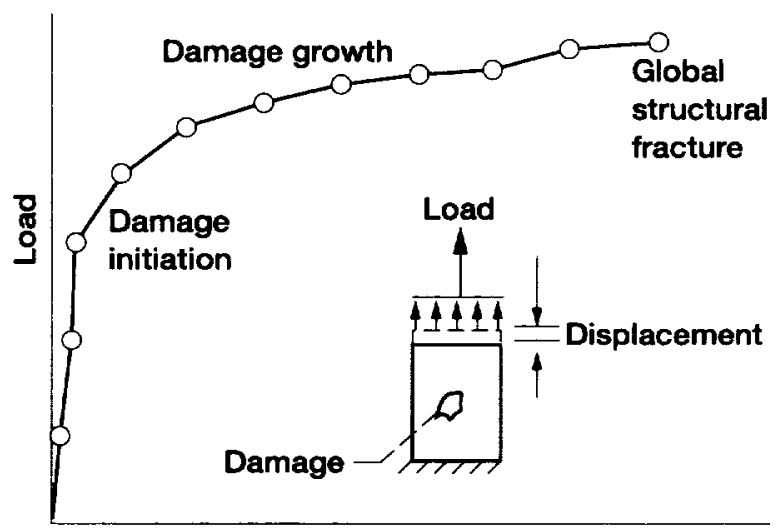

Displacement

Figure 3.-Overall CODSTRAN simulation.

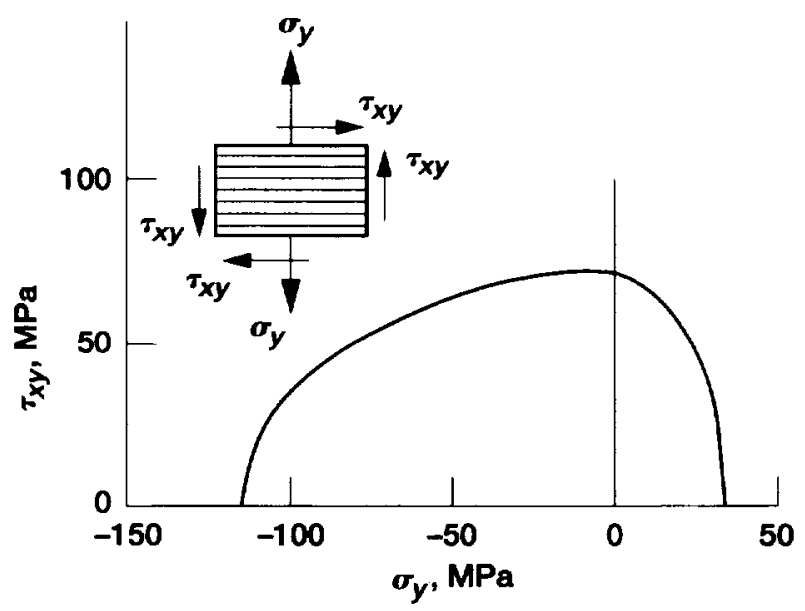

Figure 4.-Upper half of ICAN-predicted biaxial failure envelope for $0^{\circ}$ unidirectional E-Glass/LY556/HT907/ DY063 lamina, based on first-ply failure (laminate thickness $=1 \mathrm{~mm}$ ).

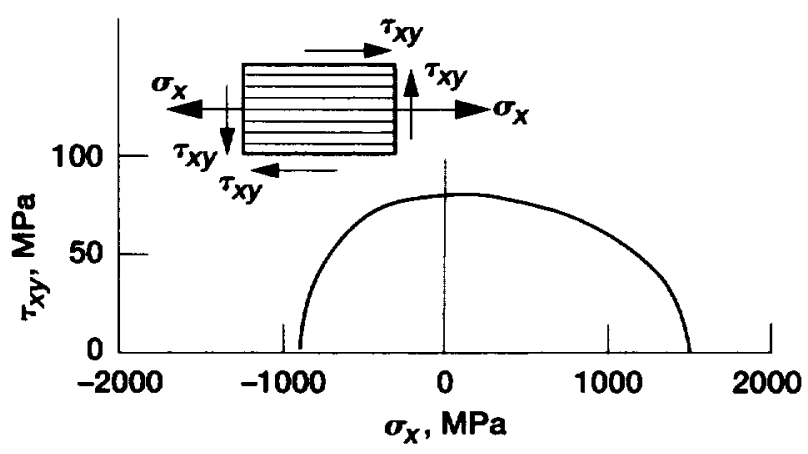

Figure 5.-ICAN-predicted biaxial failure stress envelope for $0^{\circ}$ unidirectional T300/epoxy BSL914C lamina, based on first-ply failure (laminate thickness $=1 \mathrm{~mm}$ ).

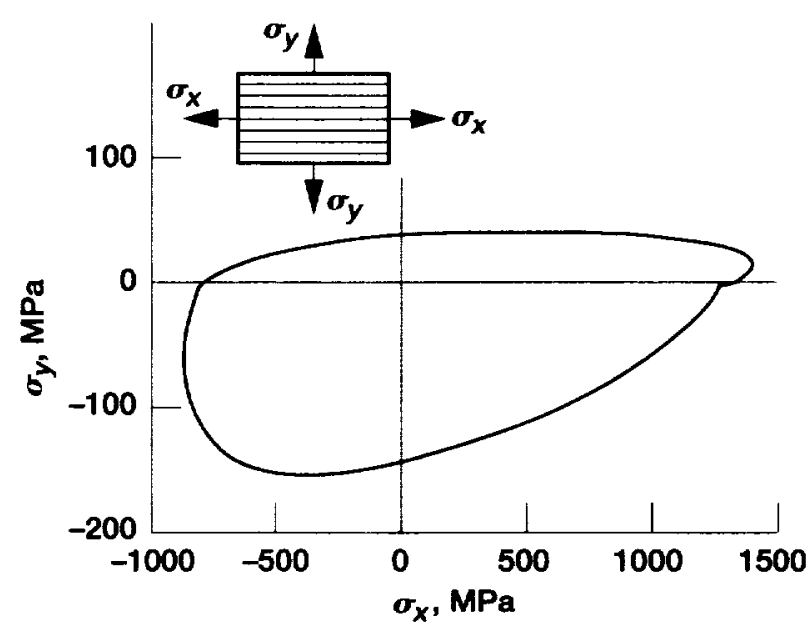

Figure 6.-ICAN-predicted biaxial failure envelope of $0^{\circ}$ unidirectional E-Glass/MY750/HY917/DY063 lamina, based on first-ply failure (laminate thickness $=1 \mathrm{~mm}$ ).

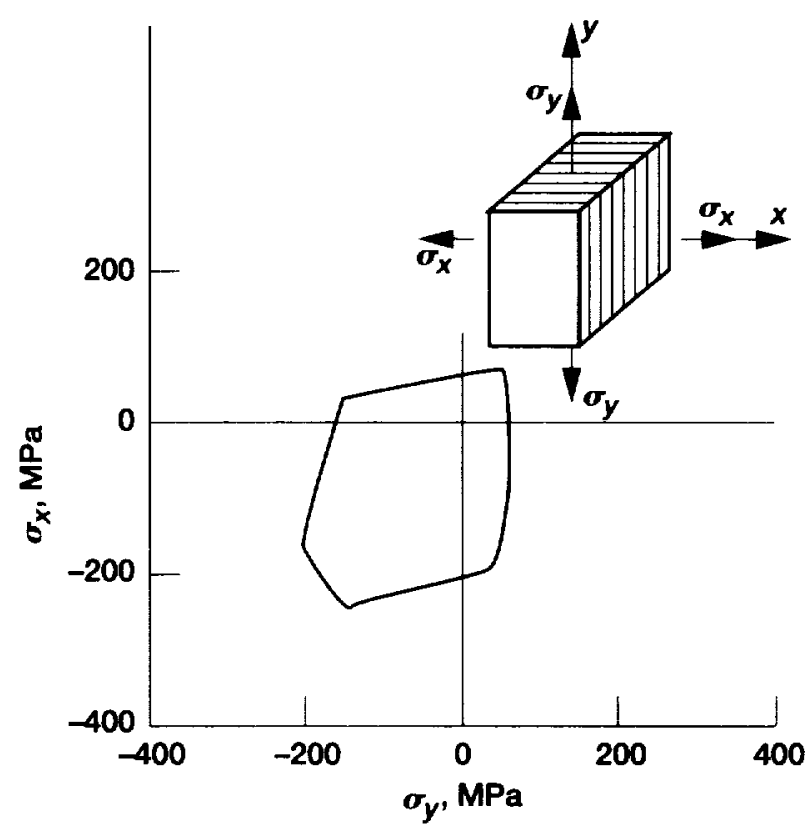

Figure 7.-ICAN-predicted biaxial failure envelope of $(90 \% 30)_{2}$ E-Glass/HT907, based on first-ply failure (laminate thickness $=2 \mathrm{~mm}$ ). 


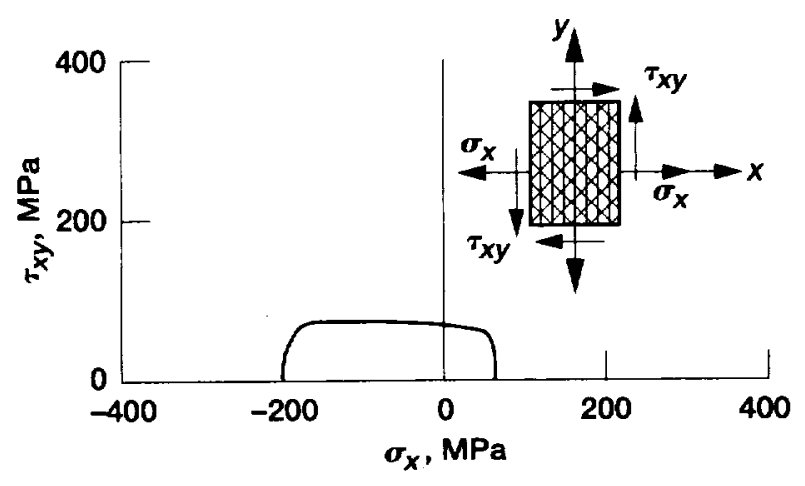

Figure 8. - Upper half of ICAN-predicted biaxial failure envelope of E-Glass/LY556/HT907, $\left(90^{\circ} / \pm 30^{\circ}\right)_{\mathbf{S}}$, based on first-ply failure (laminate thickness $=2 \mathrm{~mm}$ ).

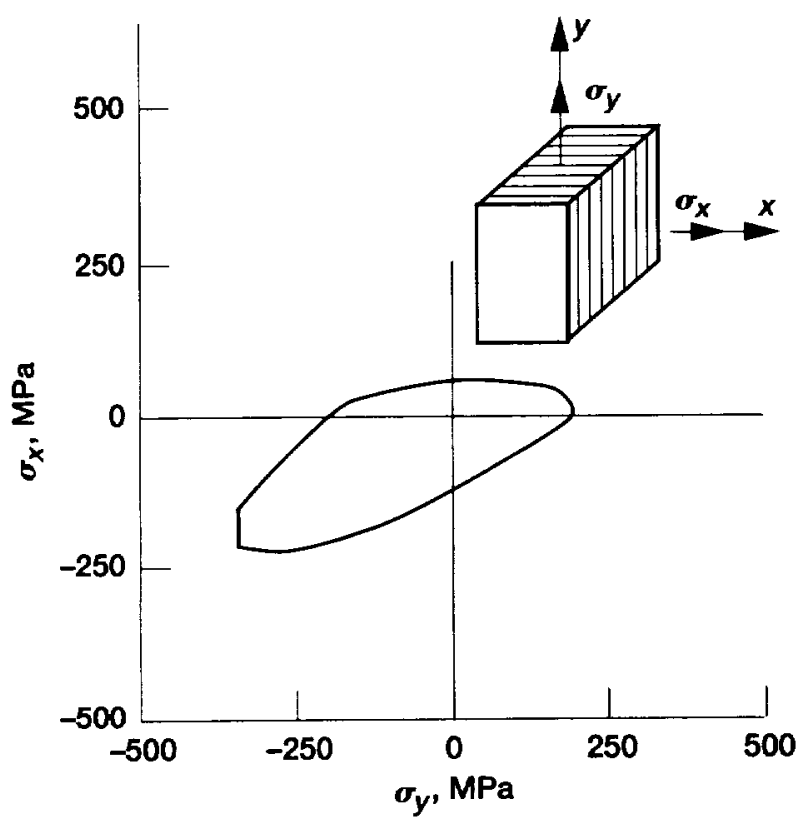

Figure 9.-ICAN-predicted biaxial stress failure envelope of $\left( \pm 55^{\circ}\right)_{s}$, E-Glass/MY750/HY917/DY063, based on first-ply failure (laminate thickness $=1 \mathrm{~mm}$ ).

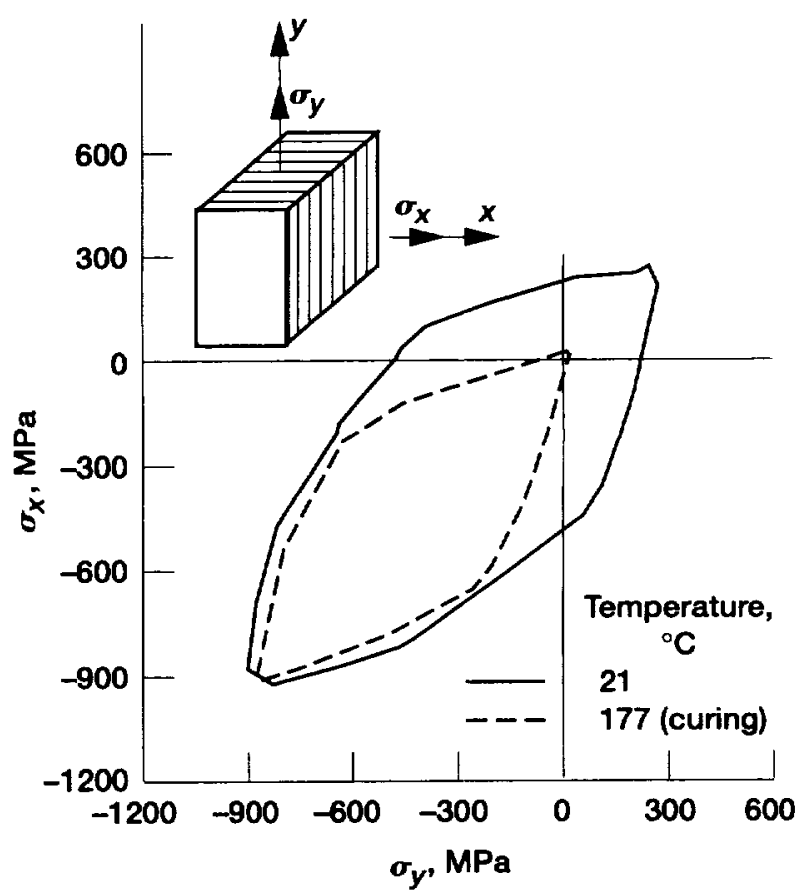

Figure 10.-ICAN-predicted biaxial failure envelope of $\left(90^{\circ} / \pm 45^{\circ} / 0^{\circ}\right)_{s}$ AS $4 /$ Epoxy $3501-6$, based on first-ply failure with and without residual stresses (laminate thickness $=1.1 \mathrm{~mm}$ ).

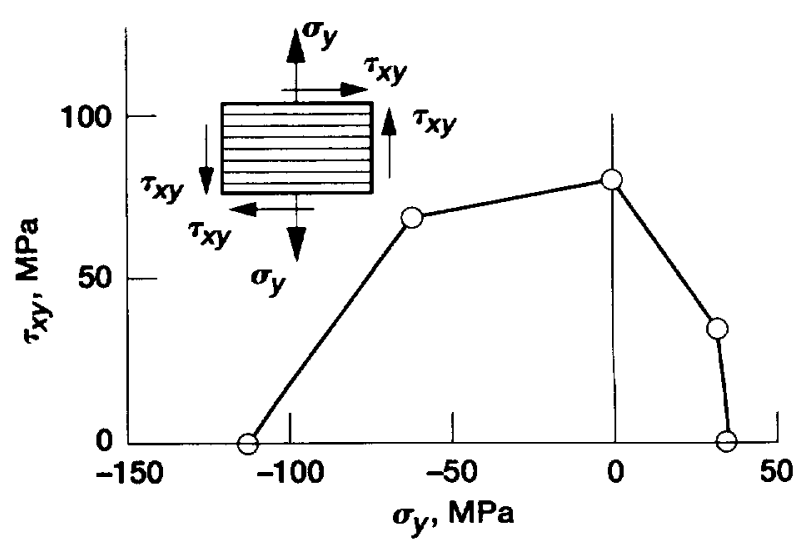

Figure 11.-CODSTRAN-predicted failure envelope of $0^{\circ}$ unidirectional E-Glass/LY556/HT907/DY063 lamina. 


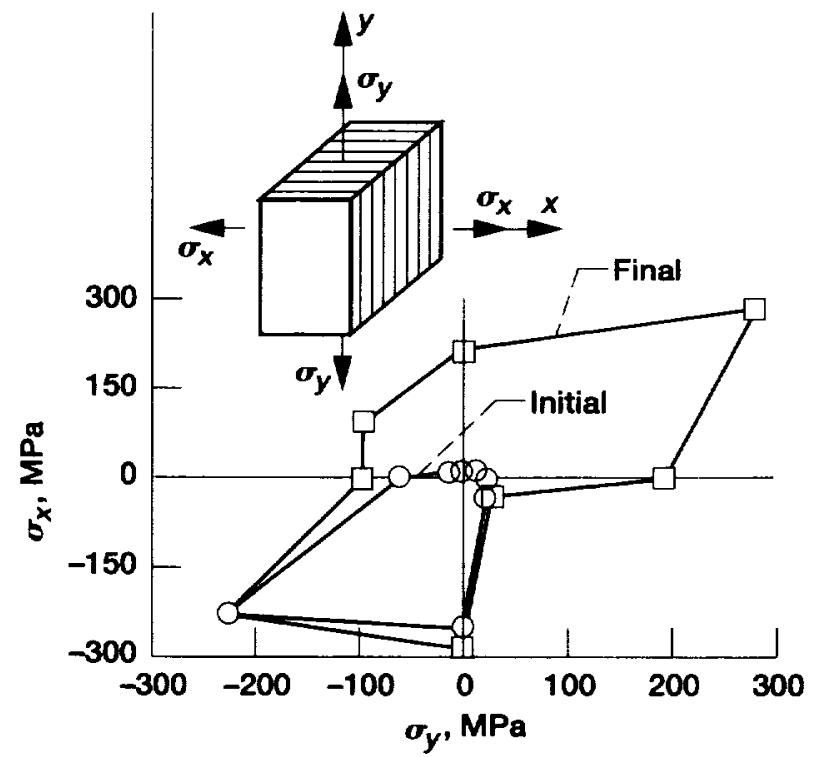

Figure 12.-Stress in $x$-direction versus stress in $y$-direction for $\left(90^{\circ} / \pm 30^{\circ} / 90^{\circ}\right)$ E-Glass/LY556/HT907/ DY063 laminate (predicted by CODSTRAN code).

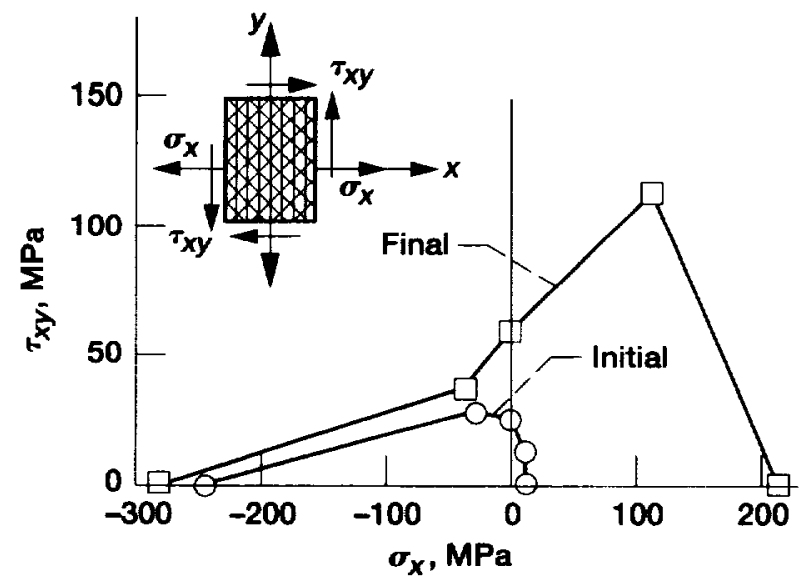

Figure 13.-Shear stress versus transverse stress for $\left(90^{\circ} / \pm 30^{\circ} / 90^{\circ}\right)$ E-Glass/LY556/HT907/DY063 laminate (predicted by CODSTRAN code).

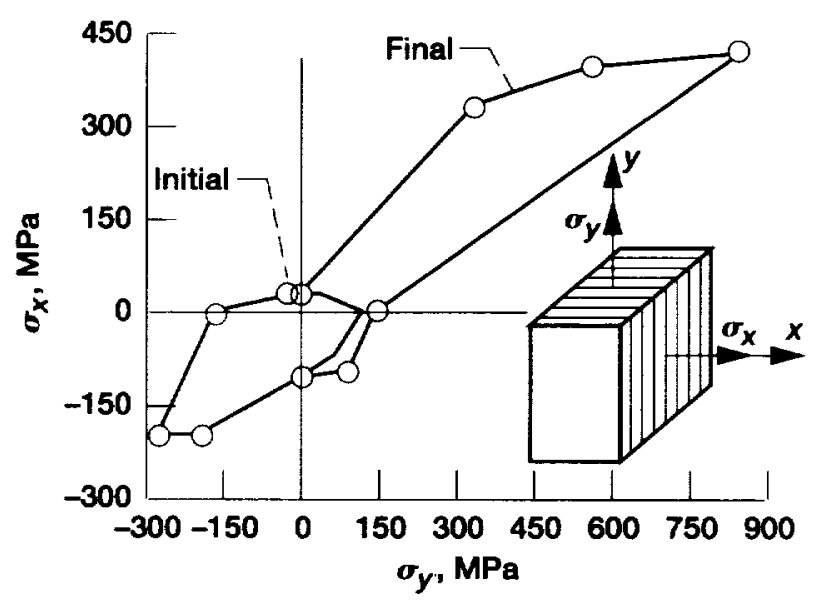

Figure 14.-Stress in $x$-direction versus stress in $y$-direction for $\pm 55^{\circ}$ E-Glass/MY750/HY917/DY063 angle-ply laminate (predicted by CODSTRAN code).

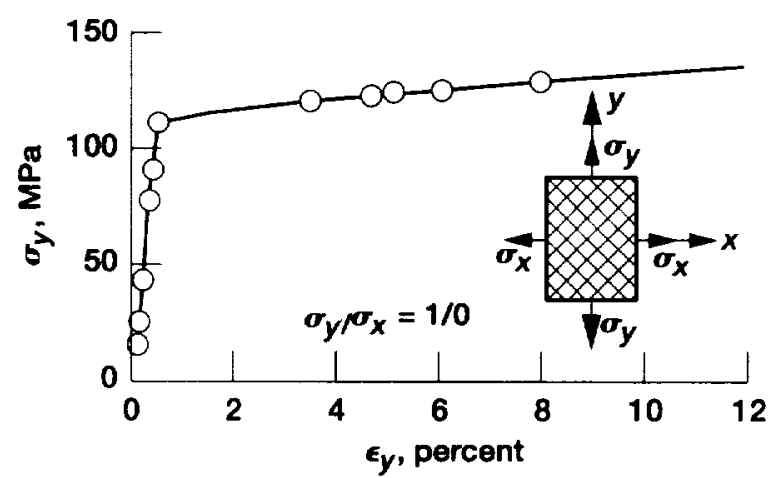

Figure 15.-Stress-strain curve for E-Glass/MY750/ HY917/DY063 $\pm 55^{\circ}$ angle-ply laminate (predicted by CODSTRAN code). 


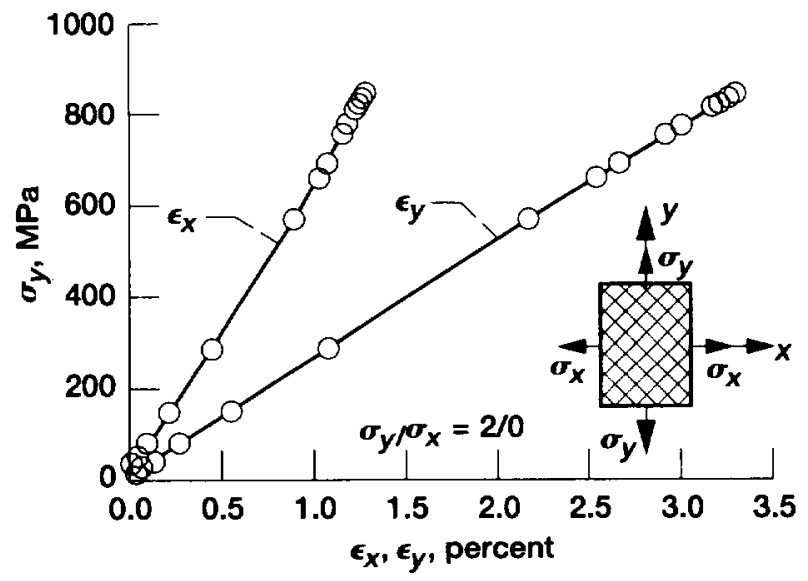

Figure 16. - Stress in $y$-direction versus strains in $x$-direction for E-Glass/MY750/HY917/DY063 $\pm 55^{\circ}$ angle-ply laminate (predicted by CODSTRAN code).

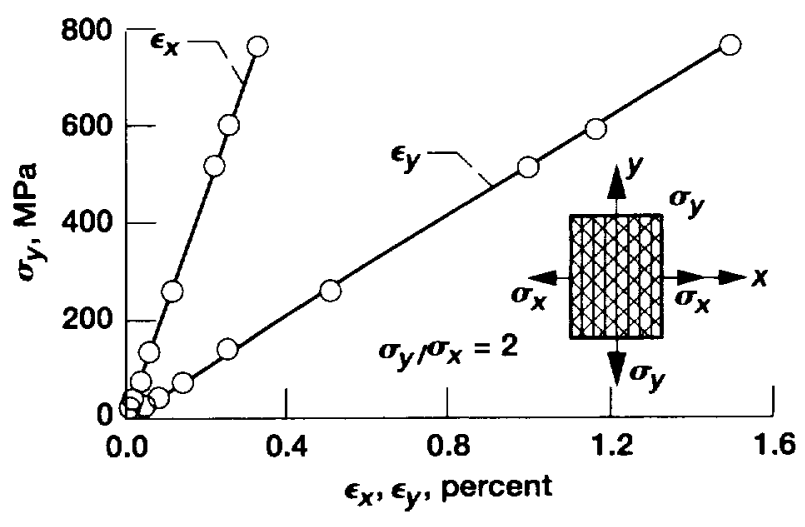

Figure 18.-Stress versus $x$ - and $y$-direction strains for AS4/3501-6 $0^{\circ} / \pm 45^{\circ} / 90^{\circ}$ quasi-isotropic laminate (predicted by CODSTRAN code).

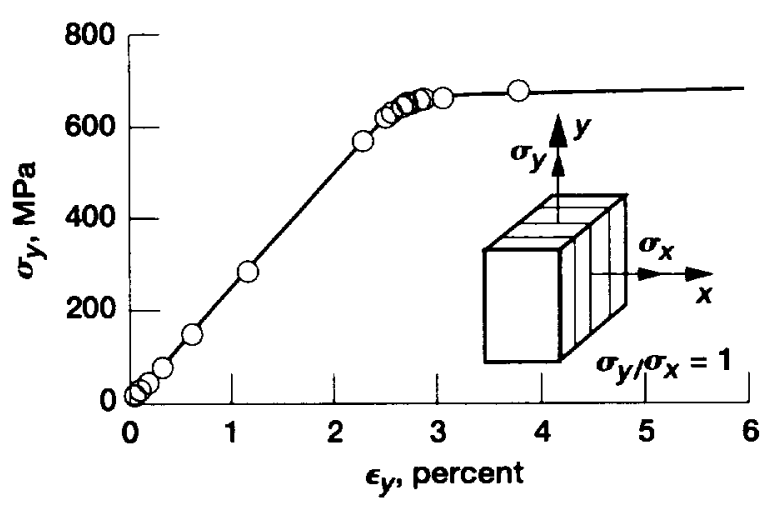

Figure 19.-Stress-strain in y-direction for E-Glass/ MY750/HY917/DY063 $\pm 45^{\circ}$ angle-ply laminate (predicted by CODSTRAN code). 


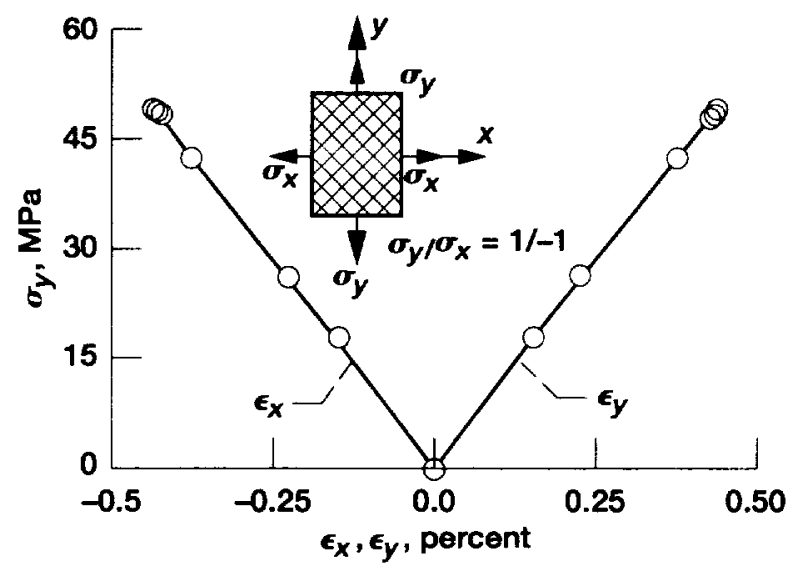

Figure 20.-Stress in $y$-direction versus strain in $x$ - and $y$-directions for E-Glass/MY750/HY917/DY063 $\pm 45^{\circ}$ angle-ply laminate (predicted by CODSTRAN code).

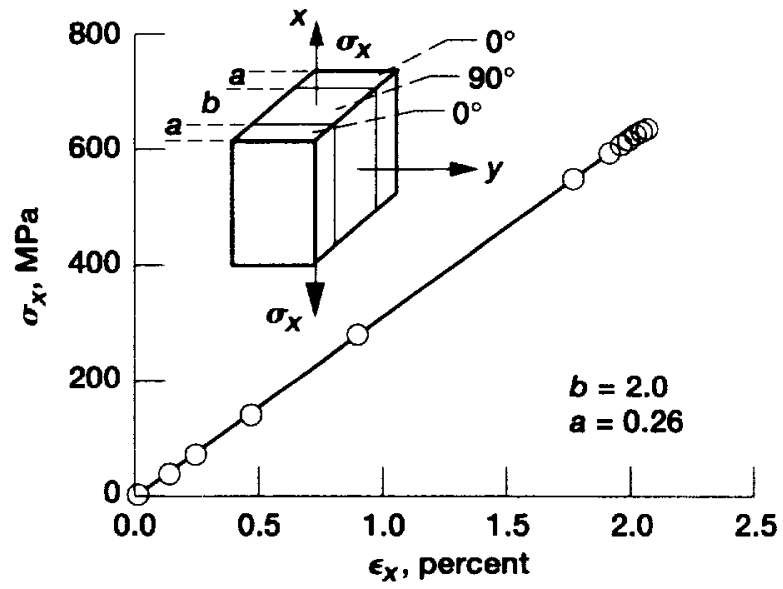

Figure 21. Stress-strain curve for E-Glass/MY750/ HY917/DY063: $0^{\circ} / 90^{\circ}$ cross-ply laminate (predicted by CODSTRAN code). 
- 
Public reporting burden for this collection of information is estimated to average 1 hour per response, including the time for reviewing instructions, searching existing data sources, gathering and maintaining the data needed, and completing and reviewing the collection of information. Send comments regarding this burden estimate or any other aspect of this collection of information, including suggestions for reducing this burden, to Washington Headquarters Services, Directorate for information Operations and Reports, 1215 Jefferson Davis Highway, Suite 1204, Artington, VA 22202-4302, and to the Office of Management and Budget, Paperwork Reduction Project (0704-0188), Washington, DC 20503.

\begin{tabular}{|l|c|c|}
\hline 1. AGENCY USE ONLY (Leave blank) & $\begin{array}{c}\text { 2. REPORT DATE } \\
\text { December } 1996\end{array}$ & $\begin{array}{r}\text { 3. REPORT TYPE AND DATES COVERED } \\
\text { Technical Memorandum }\end{array}$ \\
\hline
\end{tabular}

4. TITLE AND SUBTITLE

5. FUNDING NUMBERS

Prediction of Composite Laminate Fracture: Micromechanics and Progressive Fracture

6. AUTHOR(S)

P.K. Gotsis, C.C. Chamis, and L. Minnetyan

WU-505-63-5B

\section{PERFORMING ORganization NAME(S) AND ADDRESS(ES)}

National Aeronautics and Space Administration

Lewis Research Center

Cleveland, Ohio 44135-3191

8. PERforming ORganization REPORT NUMBER

E-10456

9. SPONSORINGMONITORING AGENCY NAME(S) AND ADDRESS(ES)

10. SPONSORINGMONTOORING AGENCY REPORT NUMBER

National Aeronautics and Space Administration

Washington, D.C. 20546-0001

NASA TM-107331

11. SUPPLEMENTARY NOTES

P.K. Gotsis and C.C. Chamis, NASA Lewis Research Center; L. Minnetyan, Clarkson University, Potsdam, New York. Responsible person, P.K. Gotsis, organization code 5210, (216) 433-3331.

12a. DISTRIBUTIONAVAILABILITY STATEMENT

12b. DISTRIBUTION CODE

Unclassified - Unlimited

Subject Category 39

This publication is available from the NASA Center for AeroSpace Information, (301) 621-0390.

13. ABSTAACT (Maximum 200 words)

This report describes an investigation to predict first-ply failure and final fracture in selected composite laminates subjected to inplane loads. The laminates were composed of glass fiber and graphite fibers in epoxy matrices. Failure envelopes based on first-ply failure and laminate fracture were generated for combined loading of these laminates. Predictions were evaluated by micromechanics-based theory and progressive fracture. The results show that, for most cases, combined tensile loading significantly enhanced the laminate fracture stress in comparison to the uniaxial loading.

\section{SUBJECT TERMS}

Glass-fibers; Graphite fibers; Epoxy matrices; Composite properties; Failure envelopes; Combined loading; Residual stress; Pristine properties; In situ properties; Stress-strain curves; Crossply; Angle ply; Multidirectional

\begin{tabular}{|c|c|c|}
\hline $\begin{array}{c}\text { 17. SECURTY CLASSIFICATION } \\
\text { OF REPORT } \\
\text { Unclassified }\end{array}$ & $\begin{array}{c}\text { 18. SECURITY CLASSIFICATION } \\
\text { OF THIS PAGE } \\
\text { Unclassified }\end{array}$ & $\begin{array}{c}\text { 19. SECURITY CLASSIFICATION } \\
\text { OF ABSTRACT } \\
\text { Unclassified }\end{array}$ \\
\hline
\end{tabular}

15. NUMBER OF PAGES 16

16. PRICE CODE A03

20. LIMITATION OF ABSTRACT

Standard Form 298 (Rev. 2-89) Prescribed by ANSI Std. Z39.18 298-102 